\title{
ORGANOMETALLIC CHEMISTRY AS A BASIS FOR UNDERSTANDING HETEROGENEOUS CATALYSIS
}

\author{
I. M. BASSET, S. L. SCOTT, A. CHOPLIN, M. LECONTE, \\ F. QUIGNARD, C. SANTINI and A. THEOLIER \\ Ecole Supérieure de Chimie Industrielle de Lvon \\ 4.3 boulevard du 11 Novembre 1918 \\ 69100 Villeurbanne Cedex \\ France
}

At the present time, our knowledge of the mechanism of action of most heterogeneous catalysts is limited. At the most primitive level, only the overall product distribution is known, while the nature of the catalyst-reactant interactions remains obscure. In a few cases, more detailed mechanistic proposals have been advanced, but they remain modest in scope compared to the detailed mechanisms that have been developed in molecular organic chemistry, and more recently, in organometallic chemistry. Indeed, even the apparently well-established catalytic mechanisms (for example, hydrogenation of olefins) are sometimes contested, indicating the fragility of the evidence on which these proposals are based. It must be recognized, however, that by comparison to strictly molecular systems, heterogeneous catalysts are intrinsically much more complicated. In addition, the application of physical methods to structural and mechanistic problems of heterogeneous systems, as well as interpretation of the results, can be difficult.

A common problem encountered in heterogeneous catalysis is the complexity of the surfaces of solid catalysts. The so-called "active sites", a concept proposed by Sir H. S. Taylor [1], may be very small in number relative to the overall surface and, consequently, their structure is almost unknown at an atomic level. It is probably this complexity which has inspired the development of surface science applied to catalysis. New concepts have emerged slowly from this approach: surface reconstruction in the presence of adsorbed molecules, surface mobility and structural reorganization of molecular-like species. It has been demonstrated that the binding of chemisorbed molecules resembles organometallic ligation (e.g., $\eta^{1}, \eta^{2}$ and $\eta^{3}$-adsorbed $C O, \pi$-bound ethylene and $\eta^{1}, \eta^{2}$ and $\eta^{3}$-ethylidene species) [2]. Naturally, the concepts derived from surface science have been, for the most part, applied to the chemisorption process and not to the reactivity pattern, although the latter is, in fact, the key to catalytic mechanisms.

At a fundamental level, we are interested in the elementary steps of heterogeneous catalytic mechanisms, that is, the succession of chemical events in which bonds of a substrate molecule are broken or created in the proximity of the surface. The number of examples in which this succession of events has been demonstrated on a well-defined surface is still limited. However, a growing awareness of this deficiency has spurred the recent development of surface organometallic chemistry $|3|$. In this relatively new field, the organometallic character of the "active site" is exploited in order to model reaction mechanisms.

During a catalytic cycle, substrates which interact with the surface form one or several chemical bonds with one or several surface atoms. Hence the "active site" is a 
supramolecule which consists of both the substrate and one or a few atoms from the surface. If the substrate is an organic molecule, as is very often the case, the "active site" has surface organometallic character and, in principle, the rules of organometallic chemistry are applicable.

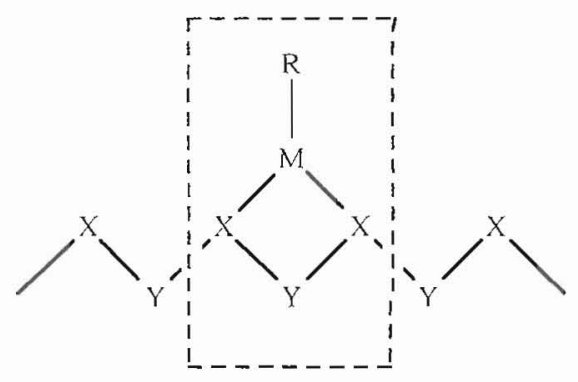

Our goal is to construct and characterise well-defined $\mathrm{su}_{\mathrm{r}}$. amolecules which resemble intermediates in surface reactions. Studies of this kind have the potential to advance understanding of heterogeneous catalysts in the same way that organometallic chemistry has been at the origin of the formulation of mechanisms in homogeneous catalysis. This motivation, among others (e.g., synthesis of tailor-made catalysts), is the driving force of surface organometallic chemistry (SOMC). The list of possible organometallic complexes includes compounds of main group elements, transition metals, lanthanides and actinides. The available surfaces encompass oxides and zero-valent metals, either of which may be highly divided materials, polycrystalline or well-defined single crystals.

\section{Reactions of Organometallic Complexes with Surfaces}

In the last decade, we and others have begun to establish the basic rules which govern the reactivity of various ligands with the functional groups which are present at the surfaces of oxides [4]. The concepts invoked are simple ones : oxidative addition, nucleophilic or electrophilic attack at the ligand or the metal center, ligand dissociation or association, electrophilic cleavage of metal carbon bonds, Brønsted and/or Lewis acid-base interactions, and redox reactions (including disproportionation), Table 1 . The determination of these rules is a necessary prerequisite to the goal of constructing a desired coordination sphere for a given reaction.

Conventional surface chemistry has revealed the diversity of surface functionalities: redox centers, acido-basic centers, nucleophilic hydroxyl groups and electrophilic protons. Surface organometallic chemistry is a new approach to probe such functionalities. In particular, the observed product distribution frequently depends on the method of pretreatment of the surface, and apparently conflicting results from different laboratories can often be attributed to variability in the support. For example, the reactions of either $\mathrm{Fe}_{3}(\mathrm{CO})_{12}$ or $\mathrm{Fe}(\mathrm{CO})_{5}$ with magnesia produce different products depending on the degree of hydration of the oxide. The chemistry of hydrated magnesia is dominated by the reactivity of strongly (Brønsted) basic surface hydroxyl groups. For both organometallic complexes, nucleophilic attack by a surface hydroxyl on coordinated $\mathrm{CO}$, followed by proton transfer, leads to the formation of $\left[\mathrm{HFe}_{3}(\mathrm{CO})_{11} \mathrm{l}^{-}\right.$and adsorbed $\mathrm{CO}_{2}[5]$. The 
Table 1. Reactions of organometallic complexes with oxide surfaces, classified by mechanism

\begin{tabular}{|c|c|c|c|c|}
\hline Mechanism & Substrate & Surface & SOM Product & Ref \\
\hline \multirow[t]{2}{*}{$\begin{array}{l}\text { Nucleophilic attack on } \\
\text { coordinated CO }\end{array}$} & $\begin{array}{c}\mathrm{M}_{3}(\mathrm{CO})_{12} \\
\mathrm{M}=\mathrm{Fe}, \mathrm{Ru}, \mathrm{Os}\end{array}$ & hydroxylated $\mathrm{MgO}$ & $\left|\mathrm{HM}_{3}(\mathrm{CO})_{11}\right|^{-}$ & $|6|$ \\
\hline & $\begin{array}{l}\mathrm{Fe}_{3}(\mathrm{CO})_{12} \\
\mathrm{Fe}(\mathrm{CO})_{5}\end{array}$ & dehydrated $\mathrm{MgO}$ & {$\left[\mathrm{Fe}(\mathrm{CO})_{4}\left(\mathrm{CO}_{2}\right)\right]^{2-}$} & $|7,8|$ \\
\hline $\begin{array}{l}\text { Electrophilic cleavage of } \\
\mathrm{M}-\mathrm{C} \text { bonds }\end{array}$ & $\mathrm{Rh}\left(\eta^{3}-\mathrm{C}_{3} \mathrm{H}_{5}\right)_{3}$ & $\begin{array}{c}\mathrm{SiO}_{2} \\
\mathrm{Al}_{2} \mathrm{O}_{3} \\
\mathrm{TiO}_{2}\end{array}$ & $(-\mathrm{SiO}) \mathrm{Rh}\left(\eta^{3}-\mathrm{C}_{3} \mathrm{H}_{5}\right)_{2}$ & |9| \\
\hline Oxidative addition & $\begin{array}{l}\mathrm{M}_{3}(\mathrm{CO})_{12} \\
\mathrm{M}=\mathrm{Ru}, \mathrm{Os}\end{array}$ & $\begin{array}{l}\mathrm{SiO}_{2} \\
\mathrm{Al}_{2} \mathrm{O}_{3}\end{array}$ & $\mathrm{M}_{3}(\mu-\mathrm{H})\left(\mu-\mathrm{OSi}=(\mathrm{CO})_{10}\right.$ & $|10|$ \\
\hline Brønsted acid-base & $\mathrm{H}_{2} \mathrm{Os}(\mathrm{CO})_{4}$ & $\mathrm{MgO}$ & {$\left[\mathrm{HOs}(\mathrm{CO})_{4}\right]^{-}$} & {$[111]$} \\
\hline Lewis acid-base & {$\left[\mathrm{HFe}_{3}(\mathrm{CO})_{11}\right\}^{-}$} & $\mathrm{MgO}$ & $\mathrm{HFe}_{3}(\mathrm{CO})_{10}(\mu-\mathrm{CO}) \rightarrow\left[\mathrm{Mg}^{2+}\right]$ & {$[5]$} \\
\hline Redox & $\begin{array}{l}\mathrm{Rh}_{6}(\mathrm{CO})_{16} \\
\mathrm{Rh}_{4}(\mathrm{CO})_{12}\end{array}$ & $\mathrm{Al}_{2} \mathrm{O}_{3}$ & $(=\mathrm{AlO}) \mathrm{Rh}^{\mathrm{l}}(\mathrm{CO})_{2}(\mathrm{OHAl}=)_{2}$ & {$[12\}$} \\
\hline Disproportionation & $\mathrm{CO}_{2}(\mathrm{CO})_{8}$ & $\mathrm{MgO}$ & $\mathrm{Co}^{2+}\left[\mathrm{Co}(\mathrm{CO})_{4}\right]_{2}$ & $|13|$ \\
\hline Promoted insertion & $\mathrm{CH}_{3} \mathrm{Mn}(\mathrm{CO})_{5} / \mathrm{CO}$ & $\mathrm{Al}_{2} \mathrm{O}_{3}$ & $(\mathrm{OC})_{5} \mathrm{Mn}\left(\mathrm{C}\left(\mathrm{CH}_{3}\right)=\mathrm{O} \rightarrow \mathrm{Al} \equiv\right)$ & {$[14]$} \\
\hline
\end{tabular}


$\left[\mathrm{HFe}_{3}(\mathrm{CO})_{11}\right]^{-}$ion is bound to the surface by a Lewis acid-base interaction between the bridging $\mathrm{CO}$ ligand and a surface $\mathrm{Mg}^{2+}$ ion, reflected by the decrease in frequency of the bridging $v(\mathrm{CO})$ mode. In contrast, magnesia dehydrated at $800{ }^{\circ} \mathrm{C}$ contains few surface hydroxyls. Reaction of a Lewis basic surface oxide ion with either $\mathrm{Fe}_{3}(\mathrm{CO})_{12}$ or $\mathrm{Fe}(\mathrm{CO})_{5}$ gives surface-bound $\mathrm{Fe}(\mathrm{CO})_{4}\left(\mathrm{CO}_{2}\right)^{2-}[7,8]$ (Figure 1).
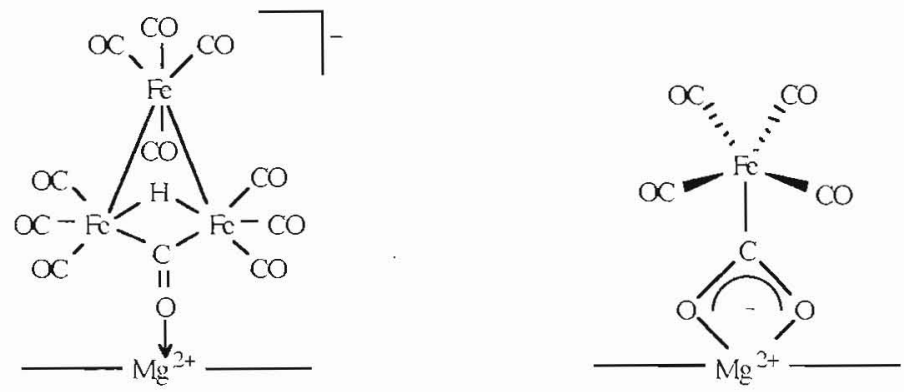

Figure 1. SOM products from the interaction of iron carbonyl clusters with magnesia.

\section{Structure and Electronic Configuration of Surface Organometallic Fragments}

Structural characterisation of surface organometallic fragments is necessary for tuning the catalytic activity of modern "tailor-made" catalysts. Due to the supramolecular character of the SOM fragment, it is necessary to use both "molecular" approaches (e.g., FTIR, solidstate NMR) and atomic determination of the structure (e.g., XPS, EXAFS). Knowledge of the precise coordination sphere of the metal will facilitate the prediction of catalytic reactions, for example, the presence of a hydride ligand for electrophilic alkane activation, a carbene for olefin metathesis, an alkyl ligand for olefin polymerization, or an oxo group for olefin oxidation. If the surface organometallic fragment has a unique structure (unfortunately not always the case), it is straightforward to deduce the electronic configuration of the metal. Based on the $(6,8,10,12,14,16,18,20)$ electron rule, one can predict the electrophilic or nucleophilic character of the metal. The following examples demonstrate how characterisation of surface organometallic species has enabled us to rationalize their structure and electronic configuration using concepts from organometallic chemistry.

The supported cluster $(\mu-\mathrm{O}-\mathrm{Si} \equiv)(\mu-\mathrm{H}) \mathrm{Os}_{3}(\mathrm{CO})_{10}, \mathbf{1}[10]$, is an 18-electron cluster in which a surface oxygen atom of silica behaves as a 3-electron ligand (in the MLH Green formalism) to the cluster. The magnesia-supported ruthenium cluster $\left[\mathrm{HR}_{13}(\mathrm{CO})_{11}\right]^{-}, \mathbf{2}$, represents a case in which the surface does not participate in formation of a covalent bond, but merely acts as a counter-cation which neutralizes the charge of the supported cluster 16]. In contrast to the analogous supported iron cluster [5], the stretching frequency of the bridging $\mathrm{CO}$ ligand is nearly unperturbed by interaction with the alumina surface, implying little direct bonding between the carbonyl oxygen and surface $\mathrm{Al}^{\mathrm{B}+}$ cations. 


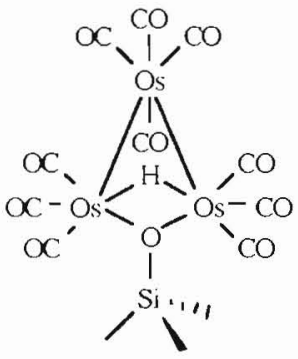

1

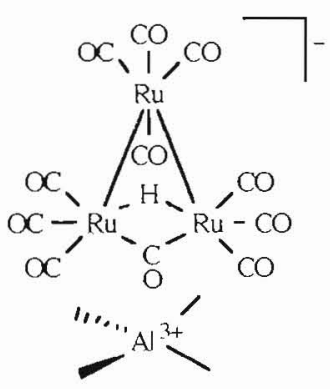

2

Tris(neopentyl)zirconium supported on silica, $\mathbf{3}$, is a highly electron-deficient surface species in which a surface oxygen atom behaves as a one-electron ligand [15]. In the presence of $\mathrm{H}_{2}$, a silica-supported zirconium hydride, $\mathbf{4}$, is formed [16]. The latter, highly electrophilic, is formally an 8-electron species which has no equivalent in molecular chemistry.

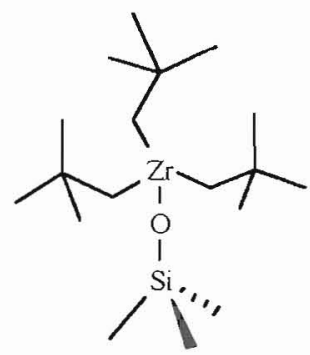

3

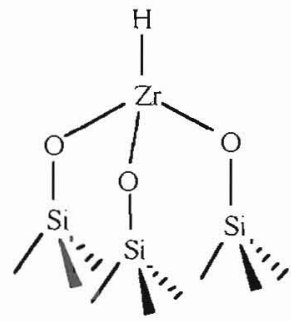

4

Bis(allyl)rhodium supported on silica, $\mathbf{5}$, has one covalent bond to a surface siloxyl. The rhodium attains an 18-electron configuration by coordination to a surface hydroxyl group [9]. On alumina and titania, which have fewer surface hydroxyls, electron donation from a surface bridging oxygen serves the same purpose, 6 .

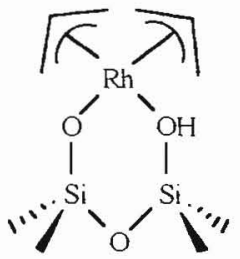

5

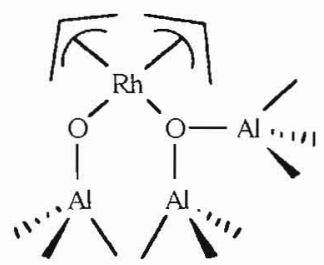

6

It is also possible to graft main group elements onto oxides by simple covalent bonds. A typical example is the formation of surface-bound $\mathrm{Sn}\left(n-\mathrm{C}_{4} \mathrm{H}_{9}\right)_{3}$ by the reaction of $\mathrm{Sn}(n$ $\left.\mathrm{C}_{4} \mathrm{H}_{9}\right)_{4}$ with silica, 7 [17]. In contrast, the same substrate reacts with the surface of metallic rhodium supported on silica to give a grafted organometallic fragment with the 
empirical formula $\mathrm{Sn}(n-\mathrm{Bu})_{2}$. The latter has the structure shown in $\mathbf{8}|18|$.

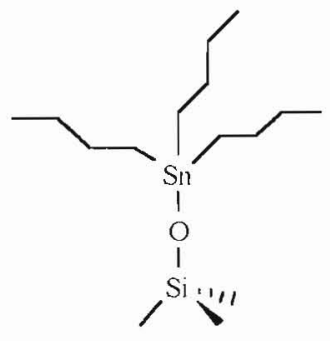

7

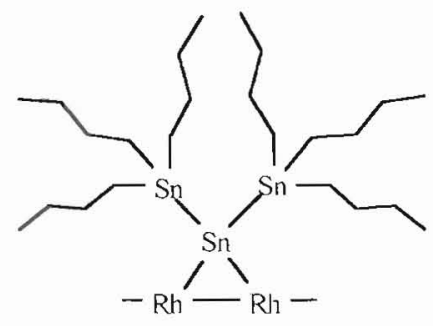

8

\section{Stoichiometric Reactivity of Surface Organometallic Fragments}

Elementary steps of homogeneous catalysis are usually deduced from known elementary steps of stoichiometric organometallic reactions: oxidative addition, insertion, reductive coupling, $\alpha, \beta$ and $\gamma$-hydrogen abstraction, metallocycle formation, etc. In heterogeneous catalysis, the elementary steps are usually unknown, and even well-identified chemisorbed molecules or molecular fragments are not necessarily reaction intermediates because of the complexity of the reaction mechanism (vide infra $\$ 4$ ). A well-chosen surface organometallic fragment may constitute an intermediate for one of these mechanisms, if the step-by-step transformation into products can be demonstrated. An illustration of this approach is the selective hydrogenolysis of alkanes by zirconium hydride supported on silica $|16|$. The $\sigma$-bond metathesis of $\mathrm{C}-\mathrm{H}$ and $\mathrm{Zr}-\mathrm{H}$ bonds, which takes place at room temperature, occurs by a 4-centre electrophilic mechanism [19].

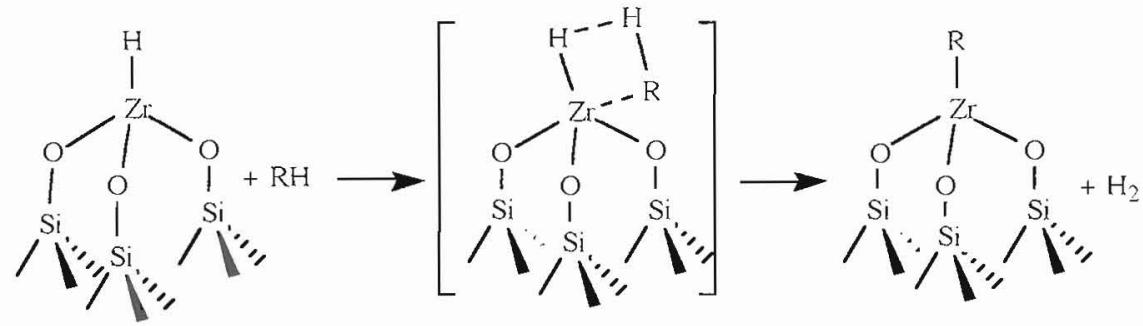

Another stoichiometric reaction whose mechanism has been identified is C-C bond formation by reductive coupling of two $\eta^{3-a l l y l ~ l i g a n d s ~ c o o r d i n a t e d ~ t o ~ s u r f a c e-b o u n d ~}$ $\mathrm{Rh}(\mathrm{III})|20|$. The reaction is initiated by addition of CO to the SOM fragment, causing the $\eta^{3}$-allyl ligands to become $\eta^{1}$-bound. The product, 1,5 -hexadiene, is formed by reductive elimination. 


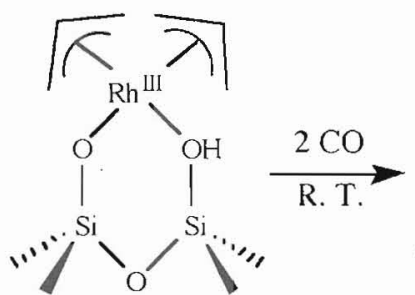

$18 \mathrm{e}^{-}$

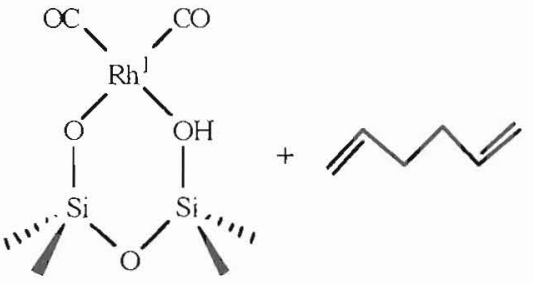

$16 \mathrm{e}^{-}$

A parallel reaction in this system is $\mathrm{CO}$ insertion into the $\eta^{1}$-allyl ligand, followed by reductive elimination of allyl and acyl ligands. The presence of 1,6-heptadien-4-one was detected among the products.
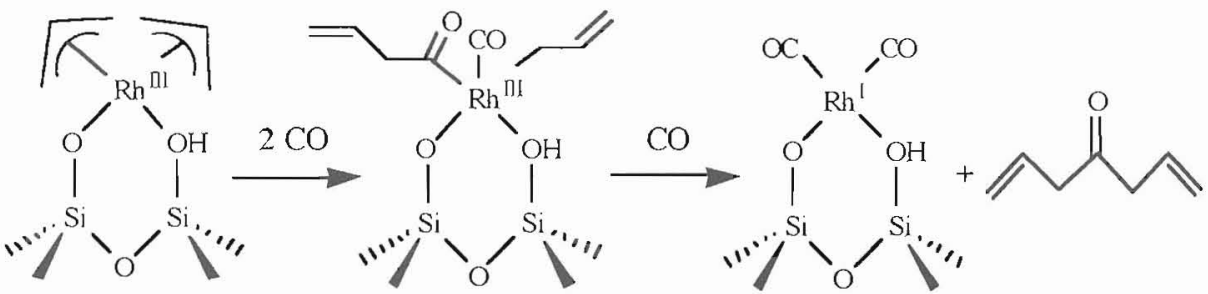

Ethylene coordinates reversibly to the supported cluster $\mathrm{Os}_{3}(\mathrm{CO})_{10}(\mu-\mathrm{H})(\mu-\mathrm{OSi} \equiv)$. At the same time, the silica ligand alternates between 3 -electron and l-electron donation as needed to maintain the optimum electron count of the cluster [10].
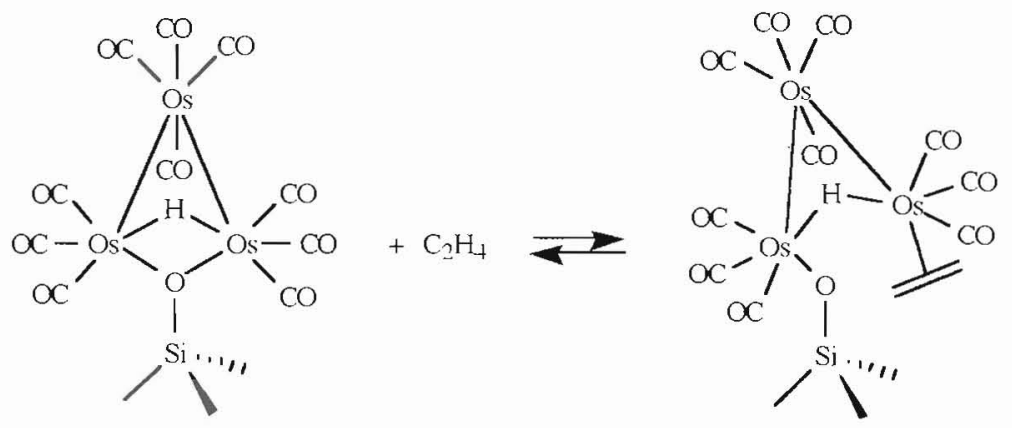

\section{The Molecular Approach to Mechanisms in Heterogeneous Catalysis}

The determination of reaction mechanisms in heterogeneous catalysis is an enormous task which will not be solved by surface organometallic chemistry alone. However, the general strategy should be based on the following considerations. In both homogeneous and heterogeneous catalysis, it is essential to extract an atomic-level understanding of catalytic processes. The surface of the heterogeneous catalyst interacting with the substrate must be viewed as a supramolecule (surface organometallic fragment). Preliminary knowledge about reactants and products must be refined with experimental evidence about intermediates and elementary steps. 
To achieve this supramolecular level of understanding, and in order to identify and characterize various intermediates formed in the conversion from reactants to products, we must develop models which reflect both structural and electronic characteristics of the catalyst. Given these structures, the rates of transformation between various intermediates must be determined, in order to reduce complicated reactions to fundamental or elementary steps that can be used in constructing reactivity models. As in homogeneous organometallic chemistry, elementary steps established for one reaction provide useful concepts for analyzing many others. The ultimate goal in these studies is, of course, to construct a mechanism which allows us to predict how to modify the rates and/or products and to design new catalysts and new processes.

Consider a generalized catalytic mechanism such as the one shown in Figure 2. The sequence of steps $\mathrm{A}+\mathrm{R} \rightarrow \mathrm{B} \rightarrow \mathrm{C} \rightarrow \mathrm{A}+\mathrm{P}$, including the detailed structures (geometric and electronic) of intermediates $\mathrm{A}, \mathrm{B}$, and $\mathrm{C}$ and the rates of transformation between them, constitutes the mechanism.

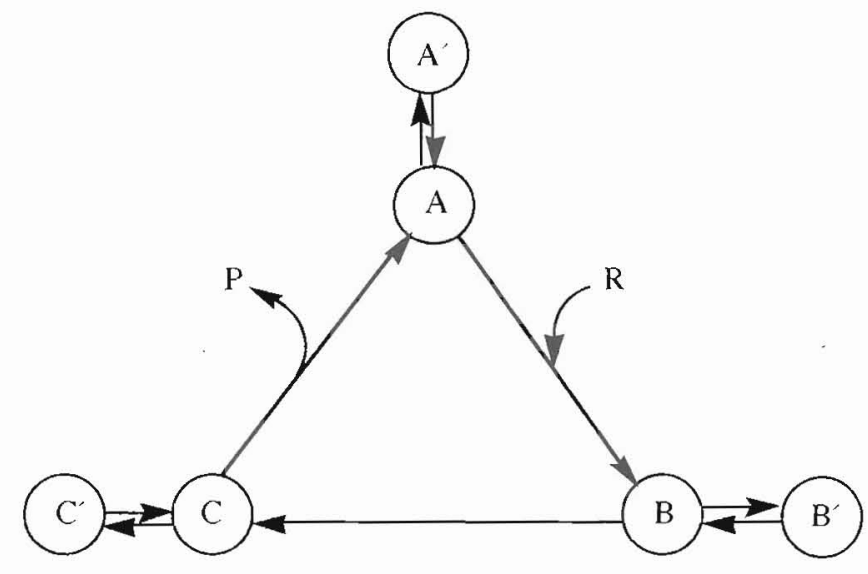

Figure 2. A typical mechanism in catalysis.

However, the actual starting point may be $\mathrm{A}^{\prime}$, which must be transformed into the active catalyst $\mathrm{A}$. Even though $\mathrm{B}^{\prime}$ and $\mathrm{C}^{\prime}$ are not involved directly in the catalytic process, they may be the dominant species observed in spectroscopic and structural experiments. It is also possible that the presence of any of the various species $A, A^{\prime}, B, B^{\prime}, C$ or $C^{\prime}$ affects the structures and rates of transformation of the other species, so that the visualization of a reaction in terms of independent species is simplified at best. Even so, snch models are crucial to extracting the concepts used to design experiments and new catalysts.

Mechanisms can be established by either (1) an experimental approach, using the techniques of homogeneous mechanistic chemistry applied to surfaces, or (2) a theoretical approach, which involves testing a mechanistic hypothesis by simulation. In order to illustrate the former, we consider the evolution of the role played by carbenes in both homogeneous and surface mechanisms. In Fischer-Tropsch eatalysis, the original mechanism, published in 1926, invoked surface carbene complexes which polymerise to give higher hydrocarbons [21]. A more complicated mechanism involving hydroxycarbene intermediates was subsequently proposed $|22|$. Later, a CO insertion mechanism gained wide acceptance [23]. However, studies of soluble models and more precise surface studies did not support the new proposals. During this period, organometallic chemists showed that carbene complexes were much more stable and prevalent than 
originally thought. The role of such species in homogeneous metathesis was established. Pettit and Brady carried out the experiments with solid catalysts that established carbene complexes as the accepted intermediates in Fisher-Tropsch catalysts $[24,25]$.

The $\mathrm{CH}_{2}$ fragment now appears to be a key intermediate in a variety of other reactions of hydrocarbons on surfaces, including hydrogenolysis and homologation of olefins and hydrocarbons (Figure 3) $[26,27,28]$.

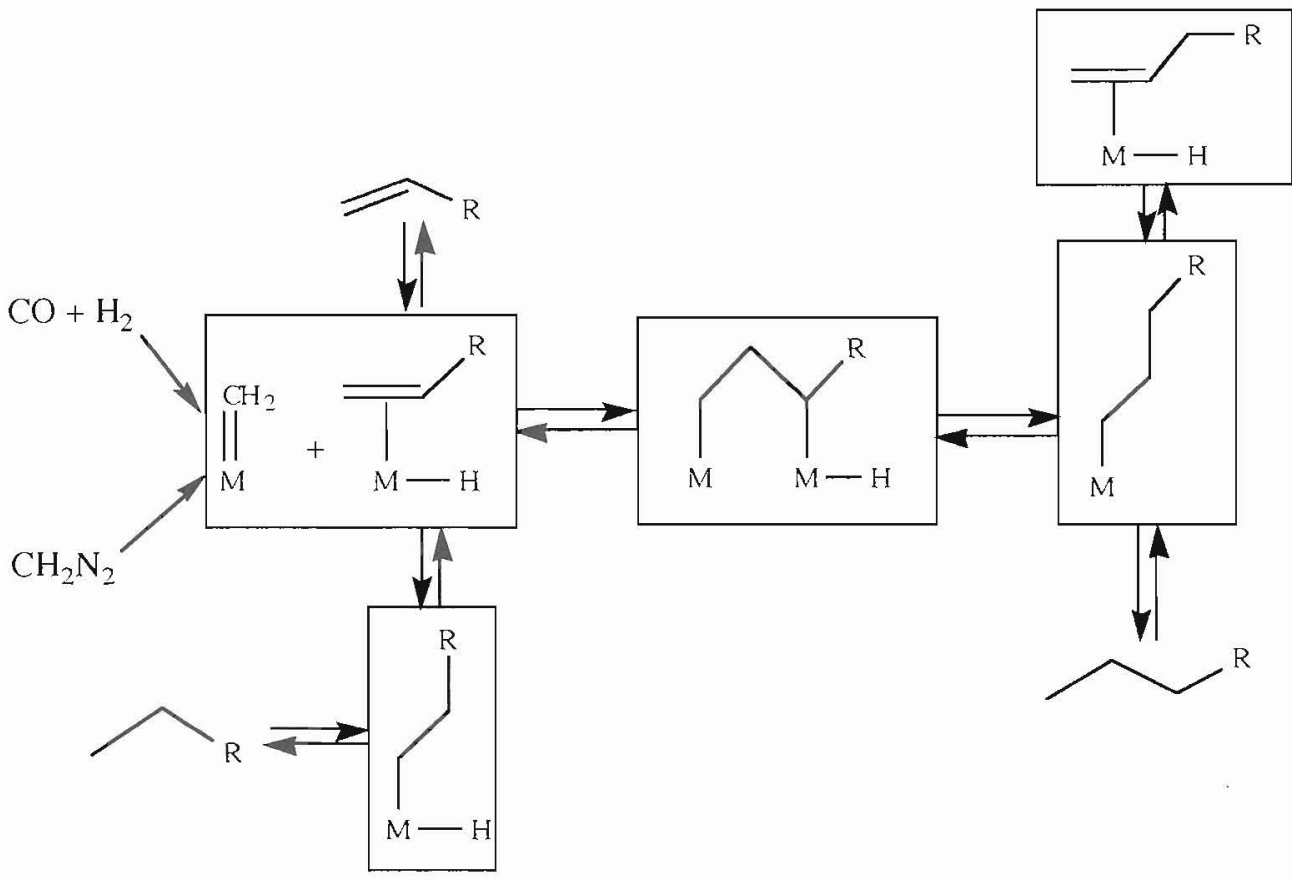

Figure 3. General mechanism for C-C bond formation and cleavage on metal surfaces.

Theory has potentially three important roles to play in elucidating the atomic-level mechanisms. First, and most important, is the establishment of general qualitative concepts concerning various elementary steps. The second role is calculation of quantitative data characterizing structures and barriers for intermediates too short-lived for detailed experimental study. Because of the complexity of surface processes and the limitations of experimental techniques, such quantitative information must, for the time being, be derived from theory. The third role of theory is the extraction of force fields from detailed molecular cluster calculations, for use in molecular dynamics and statistical simulations of complex models including all known intermediates and mechanistic steps. Such simulations, involving the dynamics of thousands of atoms, provide a strenuous test for the completeness of our molecular understanding of heterogeneous processes. Ultimately, the test of the usefulness and correctness of a theoretical approach is whether the theory suggests new approaches to improving a particular catalyst, or better, entirely new strategies for developing catalysts. 


\section{Summary and Future Prospects}

In the course of this review, we have considered the impact of molecular chemistry, organometallic chemistry and surface organometallic chemistry on the understanding of the mechanisms of action of heterogeneous catalysts. If one defines a heterogeneous mechanism as a succession of elementary steps leading from reactants to products, it is clear that a molecular approach, or more precisely an organometallic approach, will be particularly influential in elucidating those elementary steps. The primary reason is the "surface organometallic character" of the active sites of heterogeneous catalysts.

The classical approach to heterogeneous catalysis involves the study of surface structure, surface reconstruction, diffusion and chemisorption processes, but not true elementary steps. Thus, information is obtained about the "static" catalyst, and may not be relevant to the molecular transformations which occur in the catalytic cycle. In addition, classically-prepared heterogeneous catalysts generally have a very small number of active sites and, consequently, the structures being studied may not be those which are relevant to the reactivity of the catalyst. In contrast, if one grafts a carefully chosen organometallic fragment onto a surface, then the number of active sites can be quite large and the stoichiometric transformation into products is easily followed. The tools of surface science are readily applied, and those which give information at a molecular level (e.g. solid state NMR) about the structure and reactivity of supramolecular fragments are especially useful.

It appears that, in several cases, the rules of molecular organometallic chemistry can be applied to surface organometallic fragments and thus the elementary steps of heterogeneous catalysis can be described using concepts from homogeneous mechanisms. Obviously, surface studies require supplementary parameters which do not exist in molecular chemistry but which are already integrated into surface organometallic chemistry, e.g., ligand rigidity, limited translational mobility and bulk reactivity (electron reservoir properties of metallic particles, for example).

Knowledge of the rules which govern the reactivity of organometallic compounds with surfaces must precede the preparation of tailor-made catalysts. We are now in a position to design a given coordination sphere for a given catalytic reaction. The results can be quite spectacular: for example, catalytic cleavage of the $\mathrm{C}-\mathrm{C}$ bonds of alkanes has been achieved at room temperature under hydrogen with a supported zirconium hydride complex. The activity and selectivity of a catalytic reaction can be deliberately adjusted (as in molecular chemistry), in contrast to highly empirical approach to catalyst modification of classical heterogeneous catalysis. While the future of surface organometallic chemistry seems assured by the growing interest in tailor-made catalysts, further advances in the field will require a thorough fundamental characterisation of surface intermediates and elementary steps.

\section{References}

1. H. S. Taylor J. Am. Chem. Soc. 53, 578 (1931).

2. N. D. S. Canning and R. J. Madix J. Phys. Chem. 88, 2437-2446 (1984).

3. J. M. Basset, J. P. Candy, A. Choplin, B. Didillon, F. Quignard and A. Théolier, in Perspectives in Catalysis J. A. Thomas, K. I. Zamaraev, Eds. (Blackwell Scientific Publications, Oxford, 1992).

4. J. M. Basset, J. P. Candy, P. Dufour, C. Santini and A. Choplin Catalysis Today 6, I ( 1989 ).

5. F. Hugues, J. M. Basset, Y. Ben Taarit, A. Choplin, M. Primet, D. Rojas and A. K. Smith J. Am. Chem. Soc. 104, 7020-4 (1982). 
6. L. D'Ornelas, A. Théolier, A. Choplin and J. M. Basset Inorg. Chem. 27, 1261-5 (1988).

7. E. Guglielminotti and A. Zecchina J. Mol. Catal. 24, 331-44 (1984).

8. J. M. Basset, B. Besson, A. Choplin, F. Hugues, M. Leconte, D. Rojas, A. K. Smith, A. Théolier, Y. Chauvin, D. Commeruc, R. Psaro, R. Ugo and G. M. Zanderighi, in Fundamental Research in Homogeneous Catalysis M. Graziani, M. Giongo, Eds. (Plenum, New York, 1984), vol. 4, pp. 19-54.

9. P. Dufour, C. Houtman, C. C. Santini, C. Nédez, J. M. Basset, L. Y. Hsu and S. G. Shore J. Am. Chem. Soc. 114, 4248-4257 (1992).

10. A. Choplin, B. Besson, L. D'Ornelas, R. Sanchez-Delgado and J. M. Basset, J. Am. Chem. Soc: 110 2783-7 (1988).

11. H. H. Lamb and B. C. Gates, J. Am. Chem. Soc. 108, 81-9 (1986).

12. J. M. Basset, A. Théolier, D. Commeruc and Y. Chauvin J. Organomet. Chem. 279, 147 (1985).

13. N. Homs, A. Choplin, P. Ramirez de la Piscina, L. Huang, E. Garbowski, R. Sanchez-Delgado, A. Théolier and J. M. Basset Inorg. Chem. 27, 4030-3 (1988).

14. S. B. Butts, S. H. Strauss, E. M. Holt, R. E. Stimson, N. W. Alcock and D. F. Shriver J. Am. Chem. Soc. 102, 5093-5100 (1980).

15. F. Quignard, C. Lecuyer, C. Bougault, F. Lefebvre, A. Choplin, D. Olivier and J. M. Basset Inorg. Chem. 31, 928-30 (1992).

16. C. Lecuyer, F. Quignard, A. Choplin, D. Olivier and J. M. Basset Angew. Chem. Int. Ed. Engl. 30, 1660-l (1991).

17. C. Nédez, A. Choplin, F. Lefebvre, B. Benazzi and J. M. Basset J. Am. Chem. Soc., accepted for publication.

18. B. Didillon, O. Clause, F. Lefebvre, H. Lamb, C. Houtman, T. Shay, J. P. Candy and J. M. Basset, submitted for publication.

19. F. Quignard, A. Choplin and J. M. Basset J. Chem. Soc., Chem. Comm., 1589 (1991).

20. P. Dufour, S. L. Scott, C. Santini, F. Lefebvre and J. M. Basset, submitted for publication.

21. F. Fischer and H. Tropsch Brennst.-Chem. 7, 97-116 (1926); Chem. Ber. 59, 830$6(1926)$.

22. H. H. Storch, N. Golumbic and A. Anderson The Fischer-Tropsch and Related Syntheses (Wiley, New York, 1951).

23. H. Pichler and H. Schultz Chem. Ing. Tech. 12, 1160-74 (1970). C. Masters Adv. Organomet. Chem. 17, 61-103 (1979). G. Henrici-Olivé and S. Olivé Angew. Chem., Int. Ed. Engl. 15, 136-141 (1976) and references therein.

24. R. C. Brady III and R. Pettit J. Am. Chem. Soc. 102, 6182 (1980).

25. W. T. Osterloh, M. E. Cornell and R. Pettit J. Am. Chem. Soc. 104, 3759 (1982).

26. M. Leconte, A. Théolier, D. Rojas and J. M. Basset J. Am. Chem. Soc. 106, I141 (1984).

27. E. Rodriguez, M. Leconte, J. M. Basset, K. Tanaka and K. I. Tanaka J. Am. Chem. Soc. 110, 275 (1988).

28. E. Rodriguez, M. Leconte and J. M. Basset J. Catal. 132, 472 (1991). 